\title{
New Method of Measurement of the Magnetoelastic Characteristics for Tensile Stresses
}

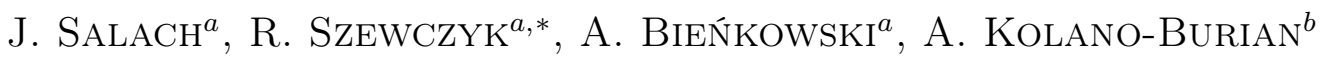 \\ AND M. FALKOWSKI ${ }^{a}$ \\ ${ }^{a}$ Institute of Metrology and Biomedical Engineering, Warsaw University of Technology \\ św. A. Boboli 8, 02-525 Warszawa, Poland \\ ${ }^{b}$ Institute of Non-ferrous Metals, Sowińskiego 5, 44-100 Gliwice, Poland
}

\begin{abstract}
The paper presents a novel method of measurements of tensile stress dependence of the magnetic characteristics of ring-shaped cores made of soft amorphous alloys. In the presented method, the uniform tensile stress was applied perpendicularly to the magnetizing field direction. Magnetoelastic core with closed magnetic circuit was fixed on the non-magnetic backings enabling the conversion of compressive force into tensile stresses as well as it enables the core to be winded by magnetizing and sensing windings. Magnetoelastic characteristics measured under tensile stress, for $\mathrm{Fe}_{25} \mathrm{Ni}_{55} \mathrm{Si}_{10} \mathrm{~B}_{10}$ alloy annealed in temperature $350{ }^{\circ} \mathrm{C}$ for $1 \mathrm{~h}$, are presented in this paper. The presented results indicate high tensile stress sensitivity of $\mathrm{Fe}_{25} \mathrm{Ni}_{55} \mathrm{Si}_{10} \mathrm{~B}_{10}$ alloy. Moreover, together with magnetoelastic characteristics for compressive stresses (presented previously in the literature), the describes results create possibility of further development of models of the magnetoelastic effects in amorphous alloys.
\end{abstract}

PACS numbers: $75.80 .+\mathrm{q}, 75.50 . \mathrm{Kj}$

\section{Introduction}

Knowledge about the magnetostrictive and magnetoelastic properties of soft amorphous alloys is very important from both practical and theoretical points of view. Changes of the length of the sample during the magnetization process (magnetostriction) causes increase of core losses as well as noise generation [1]. Thermodynamically reverse effect connected with the influence of external stresses on the magnetic properties of the alloy (so-called magnetoelastic Villari effect [2]) has also significant, technical consequences. External forces may be applied to the core during the process of component assembling or due to thermal expansion of the magnetic material. Then Villari effect causes changes of functional properties of the magnetic core [3], which may lead to malfunction of electronic device with inductive components [4].

From theoretical point of view both magnetostrictive properties [5] as well as influence of compressive stresses on magnetic characteristics [6] have been intensively investigated. On the base of results of these investigations, models of magnetization process have been developed [7]. On the other hand, results of the influence of tensile stresses on the characteristics of magnetic cores with closed magnetic circuit were not presented in the

\footnotetext{
* corresponding author; e-mail: szewczyk@mchtr.pw.edu.pl
}

literature. Lack of such data is a barrier in further development of the models of magneto-mechanical properties of magnetic materials. This paper presents a novel methodology which fills this gap and opens possibility of step forward in the area of modelling the magnetomechanical characteristics of amorphous alloys subjected to both compressive and tensile stresses.

\section{Method of investigation}

For proper testing of the magnetoelastic properties of magnetic materials two conditions should be achieved: (a) samples with closed magnetic circuit should be used and (b) uniform distribution of stresses in the tested sample should be obtained. As a result in case of strip-shaped samples, due to the appearance of demagnetization energy in total free energy of the sample, results of investigation were connected with dimensions of the sample. On the other hand, when ring-shaped samples are loaded in the direction of diameter [8], the distribution of stresses in sample is highly non-uniform.

The principle of novel method of the applying the compressive stress to the ring-shaped sample is presented in Fig. 1a. The tensile force $F$ is applied to the ring-shaped sample perpendicularly to its bases. In such case uniform, tensile stress $\sigma$ can be reached on the whole length of the magnetic circuit of the sample. It should be indicated that this methodology allows to test all commercially available, ring shaped cores made of soft ferrites, amorphous and nanocrystalline alloys. 


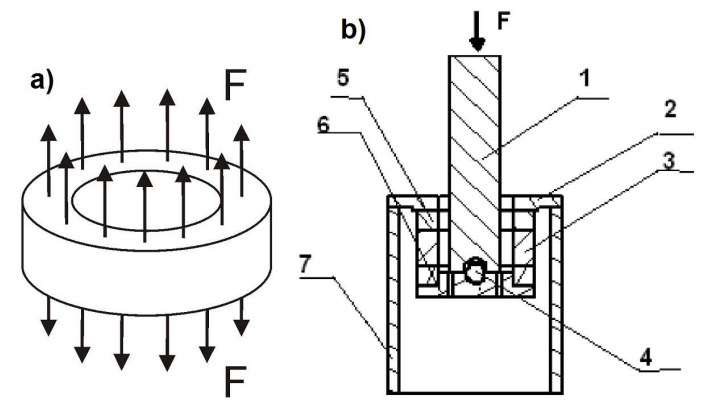

Fig. 1. Method of application of tensile stresses to the ring-shaped sample: (a) idea of the method, (b) device for practical realization of this idea: 1 - main shaft, 2 - upper backing, 3 - ring-shaped core under investigation, 4 - steel ball, $5-$ core backings, $6-$ lower backing, 7 - tube.

Device for practical realization of developed methodology is presented in Fig. 1b. Tested core (3) is fixed to core backings (5). These core backings are fixed to upper backing (2) and lower backing (6). In backings (5) and (6) special holes were drilled, to enable core to be wound by magnetizing and sensing windings. Compressive force $F$ generated by oil press is transferred by shaft (1) and ball (2) to the lower backing (6). As a result, compressive force $F$ generates uniform tensile stresses in the core (4). The magnetic properties of the samples, as well as the changes of these properties as a function of compressive stresses, were measured by digitally controlled measuring system [8].

\section{Results}

Influence of uniform tensile stresses $\sigma$ on the shape of hysteresis loop $B(H)_{\sigma}$ for the ring-shaped core made of $\mathrm{Fe}_{25} \mathrm{Ni}_{55} \mathrm{Si}_{10} \mathrm{~B}_{10}$ amorphous alloy is presented in Fig. 2. Investigated core has outside diameter $32 \mathrm{~mm}$, inside diameter $25 \mathrm{~mm}$ and height $8 \mathrm{~mm}$. Moreover, the core was annealed in temperature $350{ }^{\circ} \mathrm{C}$ for $1 \mathrm{~h}$ in presence of magnetic field $3 \mathrm{kA} / \mathrm{m}$ applied in the direction of the ribbon. Such thermomagnetic annealing generates anisotropy in the amorphous alloy, which increases magnetic permeability of the sample and may change its saturation magnetostriction $\lambda_{\mathrm{s}}\left(\lambda_{\mathrm{s}}\right.$ for as quenched sample was about $8 \mu \mathrm{m} / \mathrm{m}$ ). Under the tensile stresses up to $3 \mathrm{MPa}$, value of maximum flux density $B$ decreases from $805 \mathrm{mT}$ to $405 \mathrm{mT}$, whereas coercive field $H_{\mathrm{c}}$ slightly decreases.

The influence of tensile stress $\sigma$ on the maximum flux density $B$ in $\mathrm{Fe}_{25} \mathrm{Ni}_{55} \mathrm{Si}_{10} \mathrm{~B}_{10}$ amorphous alloy is presented in Fig. 3. The measurements were performed at the constant values of amplitude of magnetizing field $H_{\mathrm{m}}$. It should be indicated that $B\left(H_{\mathrm{m}}\right)_{\sigma}$ characteristics are monotonous, which is especially important from the point of view of sensors development. Moreover, stress sensitivity $\left|\frac{\Delta B}{B}\right|_{\sigma, H_{\mathrm{m}}}$ increases with the decrease of value of magnetizing field $H_{\mathrm{m}}$. The highest value of stress sensi-

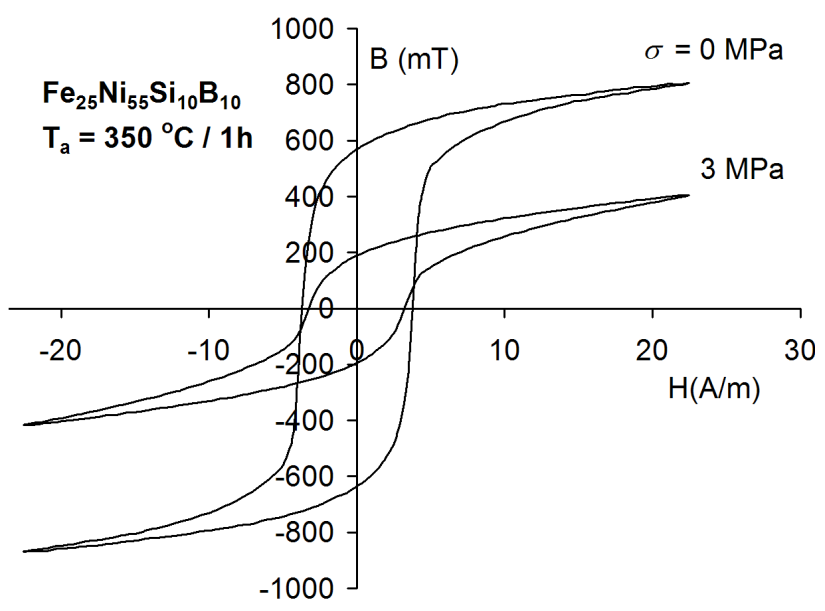

Fig. 2. Influence of tensile stresses $\sigma$ on the shape of hysteresis loop $B(H)$. Core made of $\mathrm{Fe}_{25} \mathrm{Ni}_{55} \mathrm{Si}_{10} \mathrm{~B}_{10}$ amorphous alloy annealed in temperature $350^{\circ} \mathrm{C}$ for $1 \mathrm{~h}$.

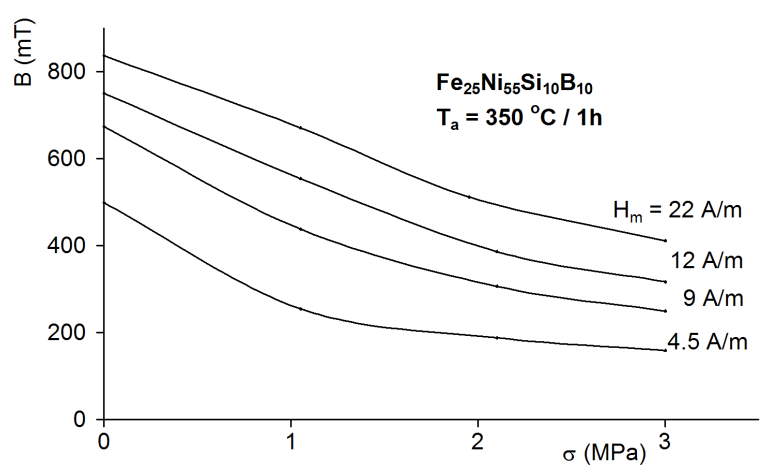

Fig. 3. The influence of tensile stress $\sigma$ on the maximum flux density $B$ in the $\mathrm{Fe}_{25} \mathrm{Ni}_{55} \mathrm{Si}_{10} \mathrm{~B}_{10}$ amorphous alloy annealed in temperature $350^{\circ} \mathrm{C}$ for $1 \mathrm{~h}$, for constant values of amplitude of magnetizing field $H_{\mathrm{m}}$.

tivity was above $150 \%$ and was observed for magnetizing field $H_{\mathrm{m}}=4.5 \mathrm{~A} / \mathrm{m}$.

\section{Conclusion}

The presented methodology of applying the tensile stress to the ring cores enables achieving the uniform distribution of stresses at the whole length of the magnetic circuit of the sample. This method made possible both fundamental research on influence of tensile stresses on magnetic characteristics of amorphous alloys as well as may be useful for construction of magnetoelastic tensile stress sensors. These possibilities of utilization amorphous alloys were not presented before.

The described results of the investigation on the influence of the tensile stress on the magnetic properties of amorphous alloys confirm their high stress sensitivity. Moreover, this sensitivity increases with the decrease of amplitude of magnetizing field $H_{\mathrm{m}}$. This phenomenon is connected with the increase of participation of magnetoelastic energy in the total free energy of the sample, due 
to the decrease of magnetostatic energy, for lower values of the magnetizing field $H_{\mathrm{m}}$.

\section{Acknowledgments}

This work was supported by Polish Ministry of Science and Higher Education within research grant N N505 465338.

This work has been supported by the European Union in the framework of European Social Fund through the Warsaw University of Technology Development Programme.

\section{References}

[1] E. Tremolet, Magnetostriction, C.R.C. Press, London 1992.
[2] D.C. Jiles, Introduction to Magnetism and Magnetic Materials, Chapman and Hall, London 1998.

[3] J. Salach, A. Bienkowski, R. Szewczyk, J. Automat. Mobile Robot. Intel. Systems 1, 66 (2007).

[4] A. Pressman, Switching Mode Power Supply Design, McGraw-Hill, New York 1998.

[5] R. Szewczyk, Pramana - J. Phys. 67, 1165 (2006).

[6] A. Bieńkowski, R. Szewczyk, Sensors Actuat. A 113, 270 (2004).

[7] F. Liorzou, B. Phelps, D.L. Atherton, IEEE Trans. Magn. 36, 418 (2000).

[8] R. Szewczyk, A. Bieńkowski, R. Kolano, Cryst. Res. Technol. 38, 320 (2003). 